\title{
SERAPILHEIRA ACUMULADA EM COMPLEXO RUPESTRE DE GRANITO, MIMOSO DO SUL, ES ${ }^{1}$
}

Carlos Antônio Araújo de Freitas², Marcos Vinicius Winckler Caldeira ${ }^{3}$, Sustanis Kunz Horn³, Kallil Chaves Castro $^{4}$ e Márcio Viera ${ }^{5}$

\begin{abstract}
RESUMO - Este estudo objetivou quantificar a biomassa, teor e conteúdo de nutrientes na serapilheira acumulada, correlacionando com a precipitação e a temperatura. A amostragem foi realizada em cinco transectos $(50 \mathrm{~m} \times 2 \mathrm{~m})$ e coletada com um gabarito $(0,25 \mathrm{~m} \times 0,25 \mathrm{~m})$, de maio de 2011 a abril de 2012, bem como separada na fração "outras espécies" (mistura de folhas, galhos, flores e frutos de diversas espécies) e fração "pseudobombax" (material da Pseudobombax aff. campestre). Utilizou-se um delineamento inteiramente casualizado com 12 tratamentos e cinco repetições para biomassa; para teores, foram 12 tratamentos e três repetições. A correlação de Pearson entre os atributos da biomassa com a pluviosidade e a temperatura foi realizada e sua significância, testada. A média acumulada foi de $8.900 \mathrm{~kg} \mathrm{ha}^{-1}$, com distribuição ao longo do ano, sendo N, Ca e Fe os nutrientes com maiores acúmulos na serapilheira. Houve correlação entre ambas as frações e variáveis climáticas para os macronutrientes $\mathrm{N}, \mathrm{P}$ e $\mathrm{S}$ e para os micronutrientes Fe e $\mathrm{Cu}$ na fração "pseudobombax".

Palavras-chave: Ciclagem de nutrientes; Variáveis climáticas; Biomassa.
\end{abstract}

\section{LITTER ACCUMULATED IN GRANITE ROCK GROUP, MIMOSO DO SUL, ES}

\begin{abstract}
This study aimed to quantify the biomass, content of nutrients in accumulated litter, correlating with rainfall and temperature. Sampling was conducted in five transects $(50 \mathrm{~m} \times 2 \mathrm{~m})$, collected with a template (0.25 m x $0.25 \mathrm{~m}$ ) from May 2011 to April 2012. Fraction was separated in "other species" (a mixture of leaves, twigs, flowers, fruits of various species), and "pseudobombax" (material of the Pseudobombax aff. campestre). A completely randomized design was used with twelve treatments and five replications for biomass; for contents: twelve treatments and three replications. The Pearson correlation between the attributes of biomass with rainfall and temperature was performed and its significance was tested. The accumulated average was $8,900 \mathrm{~kg} \mathrm{ha}^{-1}$, distributed throughout the year, $N$, Ca and Fe were the nutrients with higher accumulation in the litter. Correlation existed between both fractions and climatic variables for macronutrients: $N, P$ and $S$, and the micronutrients Fe and Cu in fraction "pseudobombax".
\end{abstract}

Keywords: Nutrient cycling; Climate variables; Biomass.

\footnotetext{
${ }^{1}$ Recebido em 03.09.2013 aceito para publicação em 07.04.2015.

${ }^{2}$ Instituto Federal Fluminense de Bom Jesus do Itabapoana, Bom Jesus do Itabapoana, RJ - Brasil. E-mail: <freitas.caa@gmail.com>.

${ }^{3}$ Universidade Federal do Espírito Santo, Centro de Ciências Agrárias, Departamento de Ciências Florestais e da Madeira, Alegre, ES - Brasil.E-mail: <mvwcaldeira@gmail.com>e < sustanishk@yahoo.com.br>.

${ }^{4}$ Universidade Federal do Espírito Santo, UFES - Brasil. E-mail: <kallil_florestal@yahoo.com.br>.

${ }^{5}$ Universidade Federal de Santa Maria, Unidade Descentralizada de Educação Superior de Silveira Martins, Silveira Martins, RS - Brasil. E-mail: <vieraflorestal@yahoo.com.br>.
} 


\section{INTRODUÇÃO}

A decomposição da camada orgânica formada pela serapilheira é o principal responsável pela ciclagem de nutrientes em ecossistemas florestais tropicais (PRICHETT, 1979). Esse processo de ciclagem de nutrientes via serapilheira (planta-solo-planta) possibilita o desenvolvimento de florestas em solos com baixos teores nutricionais (SCHUMACHER et al., 2004).

A serapilheira é todo material de origem orgânica que se deposita e se acumula sobre o solo. É composta por folhas, ramos, caule, casca, flores, frutos, sementes e material não vegetal não identificado, bem como restos de animais e fezes (OLSON, 1963; GOLLEY, 1978)

A decomposição da serapilheira ocorre pela interação de três variáveis: a natureza da comunidade dos decompositores; a qualidade do substrato, através de sua natureza (matéria orgânica e nutricional); e as condições edafoclimáticas (HEAL et al., 1997; RODRIGUES et al., 2007; CALDEIRA et al., 2010).

Segundo Heal et al. (1997), a decomposição é tão importante quanto os processos fotossintéticos em um ecossistema. O processo de decomposição faz que se mantenha a funcionalidade dos ecossistemas florestais tropicais, o que, segundo Olson (1963) e Odum (1969), depende da incorporação de seus componentes ao solo.

O acúmulo da serapilheira pode afetar a estrutura da comunidade vegetal presente no próprio sítio. Segundo Chambers e Macmahon (1994), quando a camada de serapilheira se torna muito espessa, pode atuar como impedimento ao estabelecimento de outras espécies, pois essa camada dificulta a penetração de sementes, em que a radícula, muitas vezes, não atinge o solo ou impossibilita a emergência de plântulas. Outra possibilidade é o fato de a serapilheira não afetar a comunidade de espécies, mas alterar as condições ambientais, dificultando a interação entre populações com diferentes sensibilidades à sua acumulação (FACELLI; PICKETT, 1991).

O conhecimento dos padrões de acúmulo de serapilheira facilita a compreensão do grau de fragilidade dos ecossistemas diante da ação antrópica vigente (GODINHO, 2013).

Diante do exposto, Schumacher et al. (2011) afirmaram que pouco se conhece da serapilheira, principalmente no que tange à representatividade de determinadas espécies no aporte de serapilheira em comunidades vegetais e na sazonalidade da deposição ao longo do ano.

A espécie Pseudobombax aff. campestre é endêmica da Cadeia do Espinhaço nos Estados de Minas Gerais e da Bahia, onde apresenta distribuição restrita à Chapada Diamantina, em cotas altitudinais superiores a $900 \mathrm{~m}$ em campos rupestres (CARVALHO-SOBRINHO, 2006). Na localidade do Complexo Rupestre de Granito de Mimoso do Sul, ES, a Pseudobombax aff. campestre se distribui em diversas topografias (onduladas a verticalizadas), apresenta altura média de 7,75 $\mathrm{m}$ ( \pm $3,26)$ e diâmetro médio de $46,43 \mathrm{~cm}( \pm 31,90)$ a $1,3 \mathrm{~m}$ do solo, fixando-se diretamente sobre a superfície rochosa, com epifitismo bem evidenciado (COUTO, 2013).

Nesse contexto, este trabalho teve por objetivo quantificar a serapilheira acumulada sobre o solo do Complexo Rupestre de Granito, no Município de Mimoso do Sul, ES, os nutrientes nela contidos e a contribuição da espécie Pseudobombax aff. campestre na ciclagem biogeoquímica para a comunidade em estudo.

\section{MATERIAL E MÉTODOS}

\subsection{Descrição da área de estudo}

A área de estudo está localizada na localidade

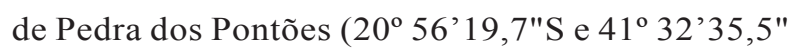
W), Município de Mimoso do Sul, Estado do Espírito Santo. Com área de aproximadamente 2,5 ha, em altitudes que variam de 700 a $783 \mathrm{~m}$, a área em foco foi estabelecida sobre um afloramento rochoso granítico. A região está inserida no domínio da Floresta Ombrófila Densa Montana (IBGE, 2012), sendo a cobertura vegetal da área classificada como Complexo Rupestre de Granito (BENITES et al., 2003).

O clima, segundo a classificação de Köppen, é do tipo Cwb, caracterizado por inverno frio e seco e verão chuvoso, com pluviosidade média anual de $1.375 \mathrm{~mm}$, com temperatura média em torno de $21^{\circ} \mathrm{C}$. A área em estudo apresenta relevo forte ondulado a acidentado e solo Neossolo Litólico (EMBRAPA, 2009).

As variáveis precipitação e temperatura média do ar no ano de estudo foram obtidas da Estação Meteorológica de Alegre, ES (2045’2,16"S e 41 '29'20,04" $\mathrm{W} ; 138 \mathrm{~m}$ de altitude), no site do Instituto Nacional de Meteorologia. A distância da estação até o local 
do Complexo Rupestre é de aproximadamente $18 \mathrm{~km}$, em linha reta.

Os atributos químicos e físicos do solo na camada de $0-10 \mathrm{~cm}$ apresentam os seguintes valores: $\mathrm{pH}\left(\mathrm{H}_{2} \mathrm{O}\right)$ de 4,5; P $32 \mathrm{mg} \mathrm{dm}^{-3}$; K $76 \mathrm{mg} \mathrm{dm}^{-3}$; $\mathrm{Na} 7 \mathrm{mg} \mathrm{dm}{ }^{-3}$; $\mathrm{Ca}$

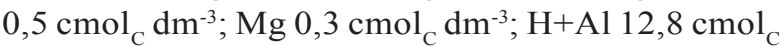
$\mathrm{dm}^{-3}$; CTC efetiva (t) $2,4 \mathrm{cmol}_{\mathrm{C}} \mathrm{dm}^{-3}$; SB $1 \mathrm{cmol}_{\mathrm{C}} \mathrm{dm}^{-3}$; V 7,4\%; Fe $44 \mathrm{mg} \mathrm{dm}^{-3}$; Cu 0,2 $\mathrm{mg} \mathrm{dm}^{-3}$; Zn 1,6 $\mathrm{mg} \mathrm{dm}^{-3}$; Mn $5 \mathrm{mg} \mathrm{dm}^{-3}$; areia $844,74 \mathrm{~g} \mathrm{~kg}^{-1}$; silte $51,53 \mathrm{~g} \mathrm{~kg}^{-1}$; e argila $103,73 \mathrm{~g} \mathrm{~kg}^{-1}$.

\subsection{Amostragem e coleta da serapilheira}

As coletas foram realizadas mensalmente, no período de maio de 2011 a abril de 2012. Foram alocados cinco transectos de $50 \mathrm{~m} \times 2 \mathrm{~m}$, sendo em cada transecto coletadas 10 amostras de serapilheira acumulada sobre o solo, com o auxílio de um gabarito de $0,25 \mathrm{~m} \mathrm{x} \mathrm{0,25}$ $\mathrm{m}$, distando $5 \mathrm{~m}$ de um ponto para o outro (coleta sistemática).

O material coletado foi separado em duas frações: fração "outras espécies", que apresentava material de diversas espécies compostas por folhas, galhos, estruturas reprodutivas, casca e resíduos na serapilheira e material não identificável; e fração "pseudobombax", provindo somente da espécie Peudobombax aff. campestre.

As amostras foram secas em estufa de circulação de ar a $65^{\circ} \mathrm{C}$ até atingirem peso constante. Após a secagem, as amostras foram pesadas em balança de precisão $(0,01 \mathrm{~g})$, para a determinação da biomassa. Posteriormente, as frações foram moídas em moinho tipo Wiley e armazenadas em frascos plásticos hermeticamente vedados, para a análise química do teor dos nutrientes (TEDESCO et al., 1995; MIYAZAWA et al., 1999).

O conteúdo de cada nutriente da serapilheira acumulada foi estimado a partir da equação 1 (CUEVAS; MEDINA, 1986):

$$
\mathrm{QNT}=[\text { Nutriente }] \times \mathrm{BSD}
$$

em que QNT = Conteúdo de nutrientes acumulados na serapilheira sobre o solo; [Nutriente ] = Teor do nutriente na serapilheira $\left(\mathrm{g} \mathrm{kg}^{-1}\right)$; e BSD = Biomassa seca da serapilheira depositada $\left(\mathrm{kg} \mathrm{ha}^{-1}\right)$.

\subsection{Análises estatísticas}

Para avaliação da variação mensal de cada fração da serapilheira acumulada e dos teores de nutrientes, considerou-se um delineamento inteiramente casualizado (DIC), com 12 tratamentos (meses do ano) e cinco repetições (transectos) para a serapilheira e três repetições para o teor de nutrientes. Os dados foram submetidos ao teste de Scott-Knott a 5\% de probabilidade (FERREIRA, 2000).

Para verificar a relação entre o acúmulo de serapilheira (das frações "outras espécies" e fração "pseudobombax") e os teores de nutrientes com as variáveis precipitação e temperatura, foi utilizada a metodologia de interpretação do coeficiente de correlação de Pearson (r), em que se estabelece um sistema de classificação, atribuindo valor qualitativo aos valores numéricos de coeficiente encontrado (SHIMAKURA, 2006). Os resultados da análise de correlação foram submetidos ao teste t a 5\% de probabilidade, para testar a sua significância.

\section{RESULTADOS}

\subsection{Serapilheira acumulada}

A média mensal acumulada nos 12 meses deste estudo foi de $8.981,7 \mathrm{~kg} \mathrm{ha}^{-1}$. Os valores de biomassa podem ser observados na Tabela 1.

Os resultados indicaram maior acúmulo de biomassa para a fração "outras espécies", com $80,4 \%$ do total acumulado; e menor para a fração "pseudobombax", com $19,6 \%$.

Ao observar os resultados da Tabela 1, constatouse que as médias mensais da fração "pseudobombax" não diferem significativamente entre si e a fração "outras espécies" diferiu $(p<0,05)$. Nesta última fração, os meses de setembro a dezembro de 2011 e fevereiro de 2012 apresentaram as maiores médias.

A análise de correlação de Pearson entre a fração “outras espécies", "pseudobombax" e o total do acúmulo de serapilheira deste estudo com as variáveis pluviosidade e temperatura demonstrou não haver correlação significativa $(\mathrm{p}<0,05)$ pelo teste $\mathrm{t}$ (Tabela 2$)$.

\subsection{Teores dos nutrientes}

Os teores médios mensais dos macronutrientes na serapilheira acumulada apresentou a seguinte ordem decrescente: $\mathrm{N}>\mathrm{Ca}>\mathrm{Mg}>\mathrm{K}>\mathrm{S}>\mathrm{P}$ para a fração "outras espécies". Na fração "pseudobombax", a ordem foi $\mathrm{Ca}>\mathrm{N}>\mathrm{Mg}>\mathrm{K}>\mathrm{S}>\mathrm{P}$ (Tabela3).

Revista Árvore, Viçosa-MG, v.39, n.4, p.671-681, 2015 
Tabela 1 - Acúmulo de serapilheira no Complexo Rupestre de Granito, em Mimoso de Sul, ES, e precipitação e temperatura média do ar no período do estudo.

Table 1 - Litter accumulation in Granite Rock Group, in Mimoso do Sul, ES; rainfall and average air temperature during the period of this study.

\begin{tabular}{|c|c|c|c|c|c|}
\hline Mês & Outras espécies & Pseudobombax & Total & Precipitação* & Temperatura* \\
\hline & & $\mathrm{kg} \mathrm{ha}^{-1}$ & & $\mathrm{~mm}$ & ${ }^{\circ} \mathrm{C}$ \\
\hline Maio/11 & $7286,5^{\mathrm{b} \backslash 1}( \pm 3398,8)^{12}$ & $1203,2^{\mathrm{a}}( \pm 1428,2)$ & $8489,6^{\mathrm{b}}( \pm 4508,6)$ & 28,0 & 21,0 \\
\hline Jun./11 & $6709,3^{b}( \pm 3453,3)$ & $1945,8^{\mathrm{a}}( \pm 1886,1)$ & $8655,1^{\mathrm{b}}( \pm 4672,4)$ & 27,0 & 20,2 \\
\hline Jul./11 & $6048,3^{\mathrm{b}}( \pm 3099,7)$ & $1568,9^{\mathrm{a}}( \pm 1668,6)$ & $7617,2^{\mathrm{b}}( \pm 3938,1)$ & 41,0 & 19,6 \\
\hline Ago./11 & $5997,7^{\mathrm{b}}( \pm 2829,9)$ & $1639,0^{\mathrm{a}}( \pm 1650,2)$ & $7636,7^{\mathrm{b}}( \pm 3888,3)$ & 4,0 & 21,6 \\
\hline Set./11 & $8425,6^{a}( \pm 3716,6)$ & $2206,6^{a}( \pm 2684,1)$ & $10632,2^{\mathrm{a}}( \pm 5010,2)$ & 32,0 & 21,4 \\
\hline Out./11 & $8319,8^{\mathrm{a}}( \pm 4035,2)$ & $1450,0^{\mathrm{a}}( \pm 1821,5)$ & $9769,8^{\mathrm{a}}( \pm 4674,8)$ & 96,5 & 23,2 \\
\hline Nov./11 & $7511,8^{\mathrm{a}}( \pm 4591,5)$ & $2218,4^{\mathrm{a}}( \pm 3984,5)$ & $9730,2^{\mathrm{a}}( \pm 4978,8)$ & 154,0 & 22,3 \\
\hline Dez./11 & $7990,5 \mathrm{a}( \pm 3490,4)$ & $1788,7^{\mathrm{a}}( \pm 2707,6)$ & $9779,2^{\mathrm{a}}( \pm 4189,3)$ & 258,2 & 24,8 \\
\hline Jan./12 & $6990,4^{\mathrm{b}}( \pm 3506,8)$ & $1702,0^{\mathrm{a}}( \pm 3970,3)$ & $8692,4^{\mathrm{b}}( \pm 4623,0)$ & 169,4 & 25,4 \\
\hline Fev./12 & $8925,0^{\mathrm{a}}( \pm 5089,7)$ & $1345,5^{\mathrm{a}}( \pm 1555,4)$ & $10270,5^{\mathrm{a}}( \pm 5650,9)$ & 17,4 & 26,8 \\
\hline Mar./12 & $6211,9^{\mathrm{b}}( \pm 3144,1)$ & $2286,1^{\mathrm{a}}( \pm 3548,7)$ & $8498,0^{\mathrm{b}}( \pm 4058,7)$ & 74,4 & 25,8 \\
\hline Abr./12 & $6188,3^{\mathrm{b}}( \pm 2756,5)$ & $1820,6^{a}( \pm 1903,9)$ & $8008,9^{\mathrm{b}}( \pm 2897,3)$ & 60,8 & 24,5 \\
\hline Média & 7217,1 & 1764,6 & 8981,7 & & \\
\hline Desvio-padrão & $\pm 1536,33$ & $\pm 958,12$ & $\pm 1810,06$ & & \\
\hline $\mathrm{CV}^{13}{ }^{13}$ & 50,62 & 145,53 & 49,81 & & \\
\hline$\%$ Biomassa & $80,40 \%$ & $19,60 \%$ & $100 \%$ & & \\
\hline
\end{tabular}

${ }^{1}$ Valores seguidos por uma mesma letra na coluna não diferem entre si, a 5\% de probabilidade, pelo teste de Scott-Knott; ${ }^{12}$ Valores entre parênteses referem-se ao desvio-padrão da média; e ${ }^{13}(\mathrm{CV} \%)$ Coeficiente de Variação.

*Fonte: INMET, 2012 .

Tabela 2 - Coeficiente de correlação de PEARSON entre as variáveis climáticas (precipitação e temperatura) e o acúmulo de serapilheira no Complexo Rupestre de Granito, em Mimoso do Sul, ES.

Table 2 - Pearson correlation coefficient between climate variables (precipitation and temperature) and the accumulation of litter in Granite Rock Group, in Mimoso do Sul, ES.

\begin{tabular}{lcc}
\hline Frações & Precipitação & Temperatura do ar \\
\hline Total & $0,29 \mathrm{~ns} *$ & $0,32 \mathrm{~ns}$ \\
Outras espécies & $0,21 \mathrm{~ns}$ & $0,30 \mathrm{~ns}$ \\
Pseudobombax & $0,22 \mathrm{~ns}$ & $0,02 \mathrm{~ns}$ \\
\hline
\end{tabular}

* Não significativo pelo teste t a $5 \%$ de probabilidade.

Os teores dos nutrientes nas frações da serapilheira diferiram significativamente entre si $(\mathrm{P}<0,05)$, bem como os teores dos macronutrientes $\mathrm{N}, \mathrm{P}$ e S apresentaram correlação significativa $((\mathrm{P}<0,05)$ com a precipitação e temperatura. Na fração "outras espécies", tanto o $\mathrm{N}$ quanto o $\mathrm{S}$ tiveram correlação negativa e significativa para a variável temperatura. A fração "pseudobombax" apresentou correlação positiva significativa para o N na variável pluviosidade e para $\mathrm{P}$ na variável temperatura.

O S na fração "pseudobombax" foi o único elemento que não apresentou diferença estatística entre os teores de nutrientes ao longo de um ano. Os demais elementos não demonstraram tendência de períodos com maior ou menor concentração.

Os teores médios dos micronutrientes nas serapilheiras acumuladas podem ser observados na Tabela 3, em que as frações apresentaram a seguinte ordem decrescente: $\mathrm{Fe}>\mathrm{Mn}>\mathrm{B}>\mathrm{Zn}>\mathrm{Cu}$.

Na Tabela 4, verifica-se que os teores de todos os elementos nas duas frações diferiram significativamente entre si $(p<0,05)$, havendo variação no acúmulo desses nutrientes dentro do período de estudo.

A análise de correlação demonstra que não foram significativas as correlações da fração "outras espécies" para ambas as variáveis climáticas (pelo teste t a 5\%). A fração "pseudobombax" apresentou correlação positiva e significativa (pelo teste t a 5\%) para os elementos Fe para pluviosidade e $\mathrm{Cu}$ para ambas as variáveis climáticas.

\subsection{Conteúdo dos nutrientes}

A ordem decrescente de acúmulo de nutrientes entre as frações foram: $\mathrm{N}>\mathrm{Ca}>\mathrm{Mg}>\mathrm{K}>\mathrm{S}>\mathrm{P}$, que representa a fração "outras espécies" e $\mathrm{Ca}>\mathrm{N}>$ 
Tabela 3 - Teores médios mensais e média anual de macronutrientes nas frações “outras espécies" e "pseudobombax” da serapilheira acumulada no Complexo Rupestre de Granito, Mimoso do Sul, ES.

Table 3 - Monthly average levels and annual average of macronutrients in the fractions "other species" and "pseudobombax" in litter accumulated in Granite Rock Group, in Mimoso do Sul, ES.

\begin{tabular}{|c|c|c|c|c|c|c|c|c|c|c|c|c|}
\hline \multirow{2}{*}{ Mês } & \multicolumn{2}{|c|}{$\mathrm{N}$} & \multicolumn{2}{|c|}{$\mathrm{P}$} & \multicolumn{2}{|c|}{$\mathrm{K}$} & \multicolumn{2}{|c|}{$\mathrm{Ca}$} & \multicolumn{2}{|c|}{$\mathrm{Mg}$} & \multicolumn{2}{|c|}{$\mathrm{S}$} \\
\hline & $\mathrm{OE}^{1}$ & $\mathrm{Psd}^{2}$ & $\mathrm{OE}$ & Psd & $\mathrm{OE}$ & Psd & $\mathrm{OE}^{1}$ & $\mathrm{Psd}^{2}$ & $\mathrm{OE}$ & Psd & $\mathrm{OE}$ & Psd \\
\hline \multicolumn{13}{|c|}{$\mathrm{g} \mathrm{kg}^{-1}$} \\
\hline Maio/11 & $\begin{array}{l}18,2^{\mathrm{c} / 3} \\
( \pm 0,4)^{14}\end{array}$ & $\begin{array}{c}10,4^{\mathrm{c}} \\
( \pm 0,2)\end{array}$ & $\begin{array}{c}0,74^{\mathrm{d}} \\
( \pm 0,04)\end{array}$ & $\begin{array}{c}0,5^{\mathrm{c}} \\
( \pm 0,0)\end{array}$ & $\begin{array}{l}0,83^{\mathrm{e}} \\
( \pm 0,3)\end{array}$ & $\begin{array}{c}0,88^{\mathrm{e}} \\
( \pm 0,0)\end{array}$ & $\begin{array}{l}12,3^{\mathrm{c} / 3} \\
( \pm 0,4)^{14}\end{array}$ & $\begin{array}{c}11,9^{\mathrm{e}} \\
( \pm 0,3)\end{array}$ & $\begin{array}{c}2,26^{\mathrm{e}} \\
( \pm 0,08)\end{array}$ & $\begin{array}{c}2,9^{\mathrm{e}} \\
( \pm 0,1)\end{array}$ & $\begin{array}{c}1,29^{\mathrm{a}} \\
( \pm 0,24)\end{array}$ & $\begin{array}{c}0,79^{\text {ns }} \\
( \pm 0,1)\end{array}$ \\
\hline Jun./11 & $\begin{array}{c}18,9^{\mathrm{b}} \\
( \pm 0,3)\end{array}$ & $\begin{array}{c}8,4^{f} \\
( \pm 0,4)\end{array}$ & $\begin{array}{c}0,74^{\mathrm{d}} \\
( \pm 0,06)\end{array}$ & $\begin{array}{l}0,33^{\mathrm{d}} \\
( \pm 0,0)\end{array}$ & $\begin{array}{c}0,76^{\mathrm{e}} \\
( \pm 0,02)\end{array}$ & $\begin{array}{c}0,96^{\mathrm{e}} \\
( \pm 0,0)\end{array}$ & $\begin{array}{c}11,8^{c} \\
( \pm 0,4)\end{array}$ & $\begin{array}{c}12,5^{\mathrm{d}} \\
( \pm 0,4)\end{array}$ & $\begin{array}{c}2,18^{f} \\
( \pm 0,03)\end{array}$ & $\begin{array}{c}3,0^{\mathrm{e}} \\
( \pm 0,1)\end{array}$ & $\begin{array}{c}1,3^{\mathrm{a}} \\
( \pm 0,3)\end{array}$ & $\begin{array}{l}0,59^{\text {ns }} \\
( \pm 0,1)\end{array}$ \\
\hline Jul./11 & $\begin{array}{c}19,6^{\mathrm{a}} \\
( \pm 0,2)\end{array}$ & $\begin{array}{c}9,5^{\mathrm{e}} \\
( \pm 0,0)\end{array}$ & $\begin{array}{c}0,81^{\mathrm{c}} \\
( \pm 0,04)\end{array}$ & $\begin{array}{c}0,4^{\mathrm{c}} \\
( \pm 0,1)\end{array}$ & $\begin{array}{c}0,81^{\mathrm{e}} \\
( \pm 0,04)\end{array}$ & $\begin{array}{c}0,8^{f} \\
( \pm 0,0)\end{array}$ & $\begin{array}{l}12,5^{\mathrm{c}} \\
( \pm 0,5)\end{array}$ & $\begin{array}{l}12,7^{\mathrm{c}} \\
( \pm 0,2)\end{array}$ & $\begin{array}{c}2,51^{\mathrm{d}} \\
( \pm 0,09)\end{array}$ & $\begin{array}{c}3,3^{\mathrm{c}} \\
( \pm 0,1)\end{array}$ & $\begin{array}{c}1,33^{\mathrm{a}} \\
( \pm 0,14)\end{array}$ & $\begin{array}{l}0,73^{\text {ns }} \\
( \pm 0,0)\end{array}$ \\
\hline Ago./11 & $\begin{array}{c}16,9^{\mathrm{c}} \\
( \pm 0,2)\end{array}$ & $\begin{array}{c}8,8^{f} \\
( \pm 0,4)\end{array}$ & $\begin{array}{c}0,82^{\mathrm{c}} \\
( \pm 0,0)\end{array}$ & $\begin{array}{c}0,4^{\mathrm{c}} \\
( \pm 0,0)\end{array}$ & $\begin{array}{c}1,37^{\mathrm{c}} \\
( \pm 0,01)\end{array}$ & $\begin{array}{c}1,5^{\mathrm{d}} \\
( \pm 0,1)\end{array}$ & $\begin{array}{r}14,1^{\mathrm{a}} \\
( \pm 0,3)\end{array}$ & $\begin{array}{c}13,1^{\mathrm{c}} \\
( \pm 0,4)\end{array}$ & $\begin{array}{c}2,65^{\mathrm{c}} \\
( \pm 0,05)\end{array}$ & $\begin{array}{c}3,1^{\mathrm{d}} \\
( \pm 0,0)\end{array}$ & $\begin{array}{c}1,05^{\mathrm{a}} \\
( \pm 0,13)\end{array}$ & $\begin{array}{l}0,63^{\text {ns }} \\
( \pm 0,0)\end{array}$ \\
\hline Set./11 & $\begin{array}{c}14,2^{\mathrm{f}} \\
( \pm 0,2)\end{array}$ & $\begin{array}{c}8,6^{\mathrm{f}} \\
( \pm 1,1)\end{array}$ & $\begin{array}{c}0,84^{\mathrm{c}} \\
( \pm 0,02)\end{array}$ & $\begin{array}{c}0,6^{\mathrm{b}} \\
( \pm 0,0)\end{array}$ & $\begin{array}{c}1,39^{\mathrm{c}} \\
( \pm 0,03)\end{array}$ & $\begin{array}{c}1,4^{\mathrm{d}} \\
( \pm 0,3)\end{array}$ & $\begin{array}{l}12,9^{\mathrm{c}} \\
( \pm 0,5)\end{array}$ & $\begin{array}{l}12,8^{c} \\
( \pm 0,5)\end{array}$ & $\begin{array}{c}2,46^{\mathrm{d}} \\
( \pm 0,08)\end{array}$ & $\begin{array}{c}2,4^{\mathrm{g}} \\
( \pm 0,1)\end{array}$ & $\begin{array}{c}0,91^{\mathrm{b}} \\
( \pm 0,07)\end{array}$ & $\begin{array}{l}0,63^{\text {ns }} \\
( \pm 0,0)\end{array}$ \\
\hline Out./11 & $\begin{array}{c}18,0^{\mathrm{c}} \\
( \pm 0,2)\end{array}$ & $\begin{array}{c}9,5^{\mathrm{e}} \\
( \pm 0,4)\end{array}$ & $\begin{array}{c}0,87^{\mathrm{c}} \\
( \pm 0,05)\end{array}$ & $\begin{array}{l}0,65^{\mathrm{a}} \\
( \pm 0,0)\end{array}$ & $\begin{array}{c}1,14^{\mathrm{d}} \\
( \pm 0,05)\end{array}$ & $\begin{array}{c}2,9^{\mathrm{a}} \\
( \pm 0,1)\end{array}$ & $\begin{array}{l}12,3^{\mathrm{c}} \\
( \pm 0,1)\end{array}$ & $\begin{array}{c}13,5^{\mathrm{b}} \\
( \pm 0,4)\end{array}$ & $\begin{array}{c}2,55^{\mathrm{d}} \\
( \pm 0,05)\end{array}$ & $\begin{array}{c}3,2^{\mathrm{c}} \\
( \pm 0,1)\end{array}$ & $\begin{array}{c}0,98^{\mathrm{b}} \\
( \pm 0,11)\end{array}$ & $\begin{array}{l}0,73^{\text {ns }} \\
( \pm 0,1)\end{array}$ \\
\hline Nov./11 & $\begin{array}{c}15,5^{\mathrm{e}} \\
( \pm 0,2)\end{array}$ & $\begin{array}{c}12,1^{\mathrm{a}} \\
( \pm 0,2)\end{array}$ & $\begin{array}{c}0,72^{\mathrm{d}} \\
( \pm 0,05)\end{array}$ & $\begin{array}{c}0,6^{\mathrm{b}} \\
( \pm 0,1)\end{array}$ & $\begin{array}{c}0,9^{\mathrm{e}} \\
( \pm 0,05)\end{array}$ & $\begin{array}{c}0,88^{\mathrm{e}} \\
( \pm 0,0)\end{array}$ & $\begin{array}{l}13,3^{\mathrm{b}} \\
( \pm 0,4)\end{array}$ & $\begin{array}{c}12,2^{\mathrm{d}} \\
( \pm 0,2)\end{array}$ & $\begin{array}{c}2,28^{\mathrm{e}} \\
( \pm 0,06)\end{array}$ & $\begin{array}{c}2,5^{\mathrm{g}} \\
( \pm 0,0)\end{array}$ & $\begin{array}{c}0,82^{\mathrm{b}} \\
( \pm 0,16)\end{array}$ & $\begin{array}{l}0,73^{\text {ns }} \\
( \pm 0,2)\end{array}$ \\
\hline Dez./11 & $\begin{array}{c}14,4^{f} \\
( \pm 0,4)\end{array}$ & $\begin{array}{c}11,3^{\mathrm{b}} \\
( \pm 0,2)\end{array}$ & $\begin{array}{c}0,51^{\mathrm{e}} \\
( \pm 0,03)\end{array}$ & $\begin{array}{c}0,6^{\mathrm{b}} \\
( \pm 0,0)\end{array}$ & $\begin{array}{c}0,66^{\mathrm{e}} \\
( \pm 0,03)\end{array}$ & $\begin{array}{c}1,3^{\mathrm{d}} \\
( \pm 0,0)\end{array}$ & $\begin{array}{c}8,9^{f} \\
( \pm 0,3)\end{array}$ & $\begin{array}{c}11,8^{\mathrm{e}} \\
( \pm 0,2)\end{array}$ & $\begin{array}{c}1,81^{\mathrm{g}} \\
( \pm 0,08)\end{array}$ & $\begin{array}{c}3,3^{\mathrm{c}} \\
( \pm 0,1)\end{array}$ & $\begin{array}{c}0,61^{\mathrm{c}} \\
( \pm 0,15)\end{array}$ & $\begin{array}{l}0,57^{\text {ns }} \\
( \pm 0,2)\end{array}$ \\
\hline Jan./12 & $\begin{array}{c}15,6^{\mathrm{e}} \\
( \pm 0,2)\end{array}$ & $\begin{array}{c}11,1^{\mathrm{b}} \\
( \pm 0,2)\end{array}$ & $\begin{array}{c}0,67^{\mathrm{d}} \\
( \pm 0,06)\end{array}$ & $\begin{array}{c}0,6^{\mathrm{b}} \\
( \pm 0,0)\end{array}$ & $\begin{array}{c}1,04^{\mathrm{d}} \\
( \pm 0,06)\end{array}$ & $\begin{array}{c}0,7^{\mathrm{f}} \\
( \pm 0,0)\end{array}$ & $\begin{array}{c}10,6^{\mathrm{d}} \\
( \pm 0,2)\end{array}$ & $\begin{array}{c}11,3^{f} \\
( \pm 0,3)\end{array}$ & $\begin{array}{c}2,08^{f} \\
( \pm 0,03)\end{array}$ & $\begin{array}{c}2,7^{\mathrm{f}} \\
( \pm 0,1)\end{array}$ & $\begin{array}{c}0,85^{\mathrm{b}} \\
( \pm 0,18)\end{array}$ & $\begin{array}{l}0,84^{\text {ns }} \\
( \pm 0,2)\end{array}$ \\
\hline Fev./12 & $\begin{array}{r}12,7^{9} \\
( \pm 0,2)\end{array}$ & $\begin{array}{c}9,6^{\mathrm{e}} \\
( \pm 0,5)\end{array}$ & $\begin{array}{c}0,58^{e} \\
( \pm 0,07)\end{array}$ & $\begin{array}{c}0,64^{\mathrm{a}} \\
( \pm 0,0)\end{array}$ & $\begin{array}{c}1,11^{\mathrm{d}} \\
( \pm 0,12)\end{array}$ & $\begin{array}{c}1,6^{\mathrm{c}} \\
( \pm 0,0)\end{array}$ & $\begin{array}{c}9,6^{\mathrm{e}} \\
( \pm 0,2)\end{array}$ & $\begin{array}{l}12,4^{\mathrm{d}} \\
( \pm 0,5)\end{array}$ & $\begin{array}{l}1,88^{\mathrm{g}} \\
( \pm 0,1)\end{array}$ & $\begin{array}{c}3,3^{\mathrm{c}} \\
( \pm 0,1)\end{array}$ & $\begin{array}{c}0,56^{\mathrm{c}} \\
( \pm 0,23)\end{array}$ & $\begin{array}{l}0,75^{\text {ns }} \\
( \pm 0,1)\end{array}$ \\
\hline Mar./12 & $\begin{array}{c}16,8^{\mathrm{d}} \\
( \pm 0,4)\end{array}$ & $\begin{array}{c}11,9^{\mathrm{a}} \\
( \pm 0,0)\end{array}$ & $\begin{array}{c}0,95^{\mathrm{b}} \\
( \pm 0,02)\end{array}$ & $\begin{array}{c}0,66^{\mathrm{a}} \\
( \pm 0,0)\end{array}$ & $\begin{array}{c}2,1^{\mathrm{a}} \\
( \pm 0,0)\end{array}$ & $\begin{array}{c}1,5^{\mathrm{c}} \\
( \pm 0,1)\end{array}$ & $\begin{array}{l}13,3^{\mathrm{b}} \\
( \pm 0,3)\end{array}$ & $\begin{array}{c}11,4^{\mathrm{f}} \\
( \pm 0,1)\end{array}$ & $\begin{array}{c}3,01^{\mathrm{a}} \\
( \pm 0,06)\end{array}$ & $\begin{array}{c}3,8^{\mathrm{a}} \\
( \pm 0,0)\end{array}$ & $\begin{array}{l}0,84^{\mathrm{b}} \\
( \pm 0,1)\end{array}$ & $\begin{array}{l}0,87^{\text {ns }} \\
( \pm 0,1)\end{array}$ \\
\hline Abr./12 & $\begin{array}{c}18,0^{c} \\
( \pm 0,2)\end{array}$ & $\begin{array}{c}10,2^{\mathrm{d}} \\
( \pm 0,4)\end{array}$ & $\begin{array}{c}1,03^{\mathrm{a}} \\
( \pm 0,02)\end{array}$ & $\begin{array}{c}0,67^{\mathrm{a}} \\
( \pm 0,0)\end{array}$ & $\begin{array}{c}1,7^{\mathrm{b}} \\
( \pm 0,08)\end{array}$ & $\begin{array}{c}2,2^{\mathrm{b}} \\
( \pm 0,1)\end{array}$ & $\begin{array}{l}13,8^{\mathrm{a}} \\
( \pm 0,2)\end{array}$ & $\begin{array}{c}14,1^{\mathrm{a}} \\
( \pm 0,1)\end{array}$ & $\begin{array}{c}2,91^{\mathrm{b}} \\
( \pm 0,09)\end{array}$ & $\begin{array}{c}3,6^{\mathrm{b}} \\
( \pm 0,1)\end{array}$ & $\begin{array}{c}1,18^{\mathrm{a}} \\
( \pm 0,18)\end{array}$ & $\begin{array}{l}0,86^{\text {ns }} \\
( \pm 0,2)\end{array}$ \\
\hline Média & 16,13 & 10,12 & 0,77 & 0,56 & 1,15 & 1,37 & 12,12 & 12,48 & 2,38 & 3,09 & 0,98 & 0,73 \\
\hline CV\% & 1,56 & 4,12 & 5,33 & 6,33 & 9,54 & 6,30 & 2,66 & 2,58 & 2,88 & 2,52 & 18,15 & 16,64 \\
\hline $\mathrm{r}^{1 / 5}$ & $-0,23$ & $0,68^{*}$ & $-0,44$ & 0,39 & $-0,3$ & $-0,1$ & $-0,5$ & $-0,42$ & $-0,41$ & $-0,08$ & $-0,52$ & $-0,07$ \\
\hline$r^{2}$ & $-0,69^{*}$ & 0,51 & $-0,14$ & $0,72 *$ & 0,41 & 0,33 & $-0,44$ & $-0,26$ & $-0,12$ & 0,41 & $-0,77 *$ & 0,45 \\
\hline
\end{tabular}

${ }^{1}(\mathrm{OE})$ fração "outras espécies"; ${ }^{2}(\mathrm{Psd})$ fração "pseudobombax"; ${ }^{3}$ Valores seguidos por uma mesma letra, na vertical, não diferem entre si, a 5\% de probabilidade, pelo teste de Scott-Knott; ${ }^{14}$ Valores entre parênteses referem-se ao desvio-padrão da média; (CV\%) Coeficiente de Variação; ${ }^{15}$ Correlação de Pearson entre teores de nutrientes e a pluviosidade $\left(\mathrm{r}^{1}\right)$ e a temperatura média do ar $\left(\mathrm{r}^{2}\right)$; *Correlação significativa a $5 \%$, pelo teste $\mathrm{T}$.

$\mathrm{Mg}>\mathrm{K}>\mathrm{S}>\mathrm{P}$ significa a fração "pseudobombax" (Tabela 5).

Com relação aos micronutrientes, o conteúdo médio total na serapilheira acumulada apresentou, em ambas as frações (Tabela 5), a seguinte ordem: $\mathrm{Fe}>\mathrm{Mn}>$ $\mathrm{B}>\mathrm{Zn}>\mathrm{Cu}$.

\section{DISCUSSÃO}

\subsection{Serapilheira acumulada}

Observa-se nos resultados da Tabela 1 que a média de acúmulo de serapilheira se assemelha à maioria das
Florestas Estacionais Deciduais e Semideciduais de característica secundária (KLEINPAUL et al., 2005; VOGEL; SCHUMACHER, 2010), assim como as Florestas Ombrófilas Mistas, Densa Submontanas e Mistas Montanas, também de caráter secundário ou muito alterada (BOREM; RAMOS, 2002; CALDEIRA et al., 2007).

Apesar de a fração "pseudobombax" não apresentar variação significativa de acúmulo ao longo do ano, na fração "outras espécies" os meses de setembro a dezembro de 2011 e fevereiro de 2012 apresentaram médias significativamente maiores, a soma da biomassa 
Tabela 4 - Teores médios mensal e anual de micronutrientes nas frações "outras espécies" e "pseudobombax" da serapilheira acumulada no Complexo Rupestre de Granito, em Mimoso do Sul, ES.

Table 4 - Monthly and annual average levels of micronutrients in the fractions "other species" and "pseudobombax" in litter accumulated in Granite Rock Group, in Mimoso do Sul, ES.

\begin{tabular}{|c|c|c|c|c|c|c|c|c|c|c|}
\hline \multirow{2}{*}{ Mês } & \multicolumn{2}{|c|}{$\mathrm{Zn}$} & \multicolumn{2}{|c|}{$\mathrm{Fe}$} & \multicolumn{2}{|c|}{$\mathrm{Mn}$} & \multicolumn{2}{|c|}{$\mathrm{Cu}$} & \multicolumn{2}{|c|}{$\mathrm{B}$} \\
\hline & $\mathrm{OE}^{1}$ & $\mathrm{Psd}^{2}$ & OE & Psd & $\mathrm{OE}$ & Psd & OE & Psd & $\mathrm{OE}$ & Psd \\
\hline & \multicolumn{10}{|c|}{$\mathrm{mg} \mathrm{kg}^{-1}$} \\
\hline Maio/11 & $\begin{array}{l}38,5^{b} \backslash 3 \\
( \pm 0,6)^{\backslash 4}\end{array}$ & $\begin{array}{c}29,8^{\mathrm{b}} \\
( \pm 0,9)\end{array}$ & $\begin{array}{c}590^{\mathrm{b}} \\
( \pm 111,6)\end{array}$ & $\begin{array}{c}135,6^{\mathrm{c}} \\
( \pm 12,8)\end{array}$ & $\begin{array}{c}630^{\mathrm{b}} \\
( \pm 30,4)\end{array}$ & $\begin{array}{l}184,8^{\mathrm{c}} \\
( \pm 6,7)\end{array}$ & $\begin{array}{c}9,4^{\mathrm{c}} \\
( \pm 0,3)\end{array}$ & $\begin{array}{c}7,4^{\mathrm{b}} \\
( \pm 0,1)\end{array}$ & $\begin{array}{c}34^{\mathrm{b}} \\
( \pm 0,7)\end{array}$ & $\begin{array}{l}36,6^{\mathrm{c}} \\
( \pm 0,5)\end{array}$ \\
\hline Jun./11 & $\begin{array}{c}37,5^{\mathrm{b}} \\
( \pm 0,6)\end{array}$ & $\begin{array}{l}24,1^{\mathrm{e}} \\
( \pm 0,4)\end{array}$ & $\begin{array}{c}601^{\mathrm{b}} \\
( \pm 254,0)\end{array}$ & $\begin{array}{c}129,6^{c} \\
( \pm 52,8)\end{array}$ & $\begin{array}{c}521^{\mathrm{d}} \\
( \pm 37,5)\end{array}$ & $\begin{array}{l}170,0^{c} \\
( \pm 6,5)\end{array}$ & $\begin{array}{c}9,3^{\mathrm{c}} \\
( \pm 0,3)\end{array}$ & $\begin{array}{c}5,0^{\mathrm{e}} \\
( \pm 0,4)\end{array}$ & $\begin{array}{c}32^{\mathrm{b}} \\
( \pm 3,8)\end{array}$ & $\begin{array}{l}35,1^{\mathrm{c}} \\
( \pm 1,0)\end{array}$ \\
\hline Jul./11 & $\begin{array}{c}41,7^{\mathrm{a}} \\
( \pm 0,1)\end{array}$ & $\begin{array}{l}27,2^{c} \\
( \pm 0,1)\end{array}$ & $\begin{array}{c}518^{\mathrm{b}} \\
( \pm 77,5)\end{array}$ & $\begin{array}{l}102,5^{c} \\
( \pm 4,3)\end{array}$ & $\begin{array}{c}748^{\mathrm{a}} \\
( \pm 14,6)\end{array}$ & $\begin{array}{l}175,5^{\mathrm{c}} \\
( \pm 4,0)\end{array}$ & $\begin{array}{c}10,4^{\mathrm{b}} \\
( \pm 0,1)\end{array}$ & $\begin{array}{c}5,9^{\mathrm{d}} \\
( \pm 0,3)\end{array}$ & $\begin{array}{c}36^{\mathrm{b}} \\
( \pm 1,3)\end{array}$ & $\begin{array}{l}35,1^{\mathrm{c}} \\
( \pm 0,8)\end{array}$ \\
\hline Ago./11 & $\begin{array}{c}33,5^{\mathrm{d}} \\
( \pm 0,3)\end{array}$ & $\begin{array}{l}25,9^{\mathrm{d}} \\
( \pm 1,1)\end{array}$ & $\begin{array}{c}302^{\mathrm{c}} \\
( \pm 39,3)\end{array}$ & $\begin{array}{c}68,0^{c} \\
( \pm 5,3)\end{array}$ & $\begin{array}{c}536^{\mathrm{d}} \\
( \pm 30,9)\end{array}$ & $\begin{array}{l}147,0^{c} \\
( \pm 1,3)\end{array}$ & $\begin{array}{c}9,7^{\circ} \\
( \pm 0,7)\end{array}$ & $\begin{array}{c}5,4^{\mathrm{e}} \\
( \pm 0,1)\end{array}$ & $\begin{array}{c}47^{\mathrm{a}} \\
( \pm 3,1)\end{array}$ & $\begin{array}{l}35,0^{\mathrm{c}} \\
( \pm 1,0)\end{array}$ \\
\hline Set./11 & $\begin{array}{c}32,9^{\mathrm{d}} \\
( \pm 1,5)\end{array}$ & $\begin{array}{l}27,3^{c} \\
( \pm 0,7)\end{array}$ & $\begin{array}{c}523^{\mathrm{b}} \\
( \pm 142,0)\end{array}$ & $\begin{array}{l}132,0^{\mathrm{c}} \\
( \pm 44,9)\end{array}$ & $\begin{array}{c}510^{\mathrm{d}} \\
( \pm 17,5)\end{array}$ & $\begin{array}{l}201,0^{c} \\
( \pm 1,8)\end{array}$ & $\begin{array}{c}7,4^{\mathrm{d}} \\
( \pm 0,4)\end{array}$ & $\begin{array}{c}6,1^{\mathrm{d}} \\
( \pm 0,4)\end{array}$ & $\begin{array}{c}42^{\mathrm{a}} \\
( \pm 1,4)\end{array}$ & $\begin{array}{l}38,0^{\mathrm{b}} \\
( \pm 0,4)\end{array}$ \\
\hline Out./11 & $\begin{array}{c}35,3^{c} \\
( \pm 0,6)\end{array}$ & $\begin{array}{l}28,5^{\mathrm{b}} \\
( \pm 0,7)\end{array}$ & $\begin{array}{c}729^{a} \\
( \pm 230,0)\end{array}$ & $\begin{array}{c}143,0^{\mathrm{c}} \\
( \pm 37,5)\end{array}$ & $\begin{array}{c}708^{a} \\
( \pm 105,6)\end{array}$ & $\begin{array}{c}188,0^{c} \\
( \pm 11,0)\end{array}$ & $\begin{array}{c}10,8^{\mathrm{b}} \\
( \pm 0,2)\end{array}$ & $\begin{array}{c}6,2^{\mathrm{d}} \\
( \pm 0,3)\end{array}$ & $\begin{array}{c}41^{\mathrm{a}} \\
( \pm 0,8)\end{array}$ & $\begin{array}{l}40,0^{\mathrm{a}} \\
( \pm 2,1)\end{array}$ \\
\hline Nov./11 & $\begin{array}{c}34,8^{c} \\
( \pm 2,5)\end{array}$ & $\begin{array}{l}29,5^{\mathrm{b}} \\
( \pm 0,7)\end{array}$ & $\begin{array}{c}544^{\mathrm{b}} \\
( \pm 166,3)\end{array}$ & $\begin{array}{c}636,0^{\mathrm{b}} \\
( \pm 241,8)\end{array}$ & $\begin{array}{c}753^{\mathrm{a}} \\
( \pm 65,4)\end{array}$ & $\begin{array}{l}215,3^{\mathrm{c}} \\
( \pm 2,8)\end{array}$ & $\begin{array}{c}9,4^{\mathrm{c}} \\
( \pm 0,3)\end{array}$ & $\begin{array}{c}7,3^{\mathrm{b}} \\
( \pm 0,4)\end{array}$ & $\begin{array}{c}30^{\mathrm{c}} \\
( \pm 1,2)\end{array}$ & $\begin{array}{l}29,0^{\mathrm{d}} \\
( \pm 1,4)\end{array}$ \\
\hline Dez./11 & $\begin{array}{c}27,4^{\mathrm{f}} \\
( \pm 0,5)\end{array}$ & $\begin{array}{c}33,2^{\mathrm{a}} \\
( \pm 1,1)\end{array}$ & $\begin{array}{c}874^{\mathrm{a}} \\
( \pm 99,2)\end{array}$ & $\begin{array}{c}1100^{\mathrm{a}} \\
( \pm 162,8)\end{array}$ & $\begin{array}{c}400^{\mathrm{e}} \\
( \pm 30,4)\end{array}$ & $\begin{array}{c}290,0^{\mathrm{b}} \\
( \pm 13,2)\end{array}$ & $\begin{array}{c}8,2^{\mathrm{d}} \\
( \pm 0,1)\end{array}$ & $\begin{array}{c}8,9^{\mathrm{a}} \\
( \pm 0,1)\end{array}$ & $\begin{array}{c}27^{\mathrm{c}} \\
( \pm 1,0)\end{array}$ & $\begin{array}{l}37,7^{\mathrm{b}} \\
( \pm 0,7)\end{array}$ \\
\hline Jan./12 & $\begin{array}{c}34,9^{\mathrm{c}} \\
( \pm 0,3)\end{array}$ & $\begin{array}{c}32,2^{\mathrm{a}} \\
( \pm 0,4)\end{array}$ & $\begin{array}{c}619^{\mathrm{b}} \\
( \pm 172,3)\end{array}$ & $\begin{array}{c}311,5^{\mathrm{c}} \\
( \pm 204,8)\end{array}$ & $\begin{array}{c}470^{\mathrm{e}} \\
( \pm 11,5)\end{array}$ & $\begin{array}{c}248,0^{\mathrm{c}} \\
( \pm 175,3)\end{array}$ & $\begin{array}{c}8,4^{\mathrm{d}} \\
( \pm 0,7)\end{array}$ & $\begin{array}{c}7,8^{\mathrm{b}} \\
( \pm 0,6)\end{array}$ & $\begin{array}{l}29,7^{c} \\
( \pm 0,8)\end{array}$ & $\begin{array}{l}26,1^{\mathrm{e}} \\
( \pm 1,1)\end{array}$ \\
\hline Fev./12 & $\begin{array}{c}29,9^{\mathrm{e}} \\
( \pm 0,8)\end{array}$ & $\begin{array}{c}32^{\mathrm{a}} \\
( \pm 1,1)\end{array}$ & $\begin{array}{c}979^{\mathrm{a}} \\
( \pm 73,2)\end{array}$ & $\begin{array}{c}97,0^{c} \\
( \pm 29,2)\end{array}$ & $\begin{array}{c}594^{\mathrm{c}} \\
( \pm 38,8)\end{array}$ & $\begin{array}{l}192,0^{\mathrm{c}} \\
( \pm 14,0)\end{array}$ & $\begin{array}{c}8,1^{\mathrm{d}} \\
( \pm 0,2)\end{array}$ & $\begin{array}{c}7,6^{\mathrm{b}} \\
( \pm 0,2)\end{array}$ & $\begin{array}{l}26,6^{c} \\
( \pm 1,3)\end{array}$ & $\begin{array}{l}33,1^{\mathrm{c}} \\
( \pm 1,1)\end{array}$ \\
\hline Mar./12 & $\begin{array}{c}39,2^{\mathrm{b}} \\
( \pm 1,2)\end{array}$ & $\begin{array}{c}29^{\mathrm{b}} \\
( \pm 0,7)\end{array}$ & $\begin{array}{c}294^{\mathrm{c}} \\
( \pm 119,7)\end{array}$ & $\begin{array}{c}108,0^{\mathrm{c}} \\
( \pm 58,7)\end{array}$ & $\begin{array}{c}586^{\mathrm{c}} \\
( \pm 16,4)\end{array}$ & $\begin{array}{l}414,0^{\mathrm{a}} \\
( \pm 77,5)\end{array}$ & $\begin{array}{c}14,6^{\mathrm{a}} \\
( \pm 1,0)\end{array}$ & $\begin{array}{c}9,1^{\mathrm{a}} \\
( \pm 0,4)\end{array}$ & $\begin{array}{c}39,7^{\mathrm{a}} \\
( \pm 9,9)\end{array}$ & $\begin{array}{l}35,0^{\mathrm{c}} \\
( \pm 1,0)\end{array}$ \\
\hline Abr./12 & $\begin{array}{c}33,6^{\mathrm{d}} \\
( \pm 0,2)\end{array}$ & $\begin{array}{c}19,9^{\text {f }} \\
( \pm 0,3)\end{array}$ & $\begin{array}{c}795^{\mathrm{a}} \\
( \pm 54,8)\end{array}$ & $\begin{array}{c}73,5^{\mathrm{c}} \\
( \pm 42,0)\end{array}$ & $\begin{array}{c}597^{\mathrm{c}} \\
( \pm 45,1)\end{array}$ & $\begin{array}{l}143,0^{c} \\
( \pm 8,9)\end{array}$ & $\begin{array}{c}10,4^{\mathrm{b}} \\
( \pm 0,1)\end{array}$ & $\begin{array}{c}6,7^{\mathrm{c}} \\
( \pm 0,1)\end{array}$ & $\begin{array}{l}42,8^{\mathrm{a}} \\
( \pm 1,5)\end{array}$ & $\begin{array}{l}39,7^{\text {a }} \\
( \pm 1,2)\end{array}$ \\
\hline Média & 34,9 & 28,2 & 614,0 & 253,0 & 588,0 & 214,0 & 9,7 & 7,0 & 35,7 & 35,0 \\
\hline CV\% & 2,90 & 2,64 & 23,38 & 42,61 & 7,62 & 26,09 & 4,88 & 4,86 & 9,36 & 3,15 \\
\hline $\mathrm{r}^{115}$ & $-0,42$ & 0,53 & 0,3 & $0,9^{*}$ & $-0,3$ & 0,46 & $-0,13$ & $0,61 *$ & $-0,51$ & $-0,29$ \\
\hline $\mathrm{r}^{2}$ & $-0,53$ & 0,39 & 0,43 & 0,2 & $-0,32$ & 0,51 & 0,13 & $0,74 *$ & $-0,29$ & $-0,19$ \\
\hline
\end{tabular}

${ }^{1}(\mathrm{OE})$ fração "outras espécies"; ${ }^{2}(\mathrm{Psd})$ fração "pseudobombax"; ${ }^{3}$ Valores seguidos por uma mesma letra, na vertical, não diferem entre si, a 5\% de probabilidade, pelo teste de Scott-Knott; ${ }^{1}$ Valores entre parênteses referem-se ao desvio-padrão da média; (CV\%) Coeficiente de Variação; ${ }^{\lessgtr}$ Correlação de Pearson entre teores de nutrientes e a pluviosidade $\left(\mathrm{r}^{1}\right)$ e a temperatura média do ar $\left(\mathrm{r}^{2}\right) ;{ }^{*}$ Correlação significativa a $5 \%$, pelo teste T.

Tabela 5 - Conteúdo de macro e micronutrientes acumulados pela serapilheira nas frações "outras espécies", "pseudobombax" e total no Complexo Rupestre de Granito, em Mimoso do Sul, ES.

Table 5 - Content of macronutrients and micronutrients accumulated in litter by fraction "other species", "pseudobombax" and the total in Granite Rock Group, in Mimoso do Sul, ES.

\begin{tabular}{|c|c|c|c|c|c|c|c|}
\hline & \multicolumn{3}{|c|}{ Conteúdo de macronutrientes } & & \multicolumn{3}{|c|}{ Conteúdo de micronutrientes } \\
\hline & $\mathrm{OE}^{1}$ & $\operatorname{Psd}^{2}$ & Total & & $\mathrm{OE}^{1}$ & $\mathrm{Psd}^{2}$ & Total \\
\hline & \multicolumn{3}{|c|}{$-\mathrm{kg} \mathrm{ha}^{-1} \mathrm{ano}^{-1}$} & & \multicolumn{3}{|c|}{$\mathrm{g} \mathrm{ha}^{-1} \mathrm{ano}^{-1}$} \\
\hline $\mathrm{N}$ & 118,9 & 17,9 & 136,9 & $\mathrm{Zn}$ & 249,8 & 49,6 & 299,4 \\
\hline $\mathrm{P}$ & 5,5 & 1,0 & 6,5 & $\mathrm{Fe}$ & 4553,8 & 467,1 & 5020,9 \\
\hline K & 8,2 & 2,4 & 10,6 & Mn & 4233,2 & 389,2 & 4622,4 \\
\hline $\mathrm{Ca}$ & 86,5 & 21,9 & 108,5 & $\mathrm{Cu}$ & 68,8 & 12,3 & 81,2 \\
\hline $\mathrm{Mg}$ & 16,9 & 5,5 & 22,5 & B & 255,1 & 61,7 & 316,8 \\
\hline $\mathrm{S}$ & 6,9 & 1,3 & 8,2 & & & & \\
\hline
\end{tabular}

${ }^{1}(\mathrm{OE})$ fração "outras espécies"; 2 (Psd) fração "pseudobombax".

Revista Árvore, Viçosa-MG, v.39, n.4, p.671-681, 2015 
de ambas as frações afeta diretamente o total da biomassa acumulada e os meses significativamente maiores foram entre setembro e dezembro de 2011 e fevereiro de 2012.

Segundo Wedderburn e Carter (1999), muitos fatores influenciam as diferenças mensais do acúmulo de serapilheira, podendo ser esses os fatores do ambiente, como temperatura e umidade. Burghouts et al. (1994), em estudo realizado em uma floresta da Malásia, observaram dois picos anuais de queda de serapilheira, um na estação seca e outro na chuvosa, quando esses autores consideraram a umidade do solo o fator mais determinante.

Dias et al. (2002), em estudo no Parque Estadual de Ibitipoca (área de Complexo Rupestre de altitude), no Município de Lima Duarte, MG, demonstraram que a vegetação se encontrava em distribuição na forma de mosaico e estava aparentemente controlada pela profundidade do solo, associada, assim, à permanência da água no sistema.

As plantas dos campos de altitude apresentam o seu controle de abertura de estômatos através da ação do ácido abscísico, de forma a controlar sua evapotranspiração, que, muitas vezes, pode inibir seu crescimento (TAIZ; ZEIGER, 1991), assim como apresenta estruturas morfológicas e biológicas (folhas com convergência de formas, coriáceas, pilosas e disposição vertical; caules tortuosos e suberosos; raízes mais grossas), adaptadas ao estresse hídrico (FIGUEIRA; VASCONCELOS NETO, 1991).

Diante do que esses autores afirmaram, a vegetação do Complexo Rupestre deste estudo em ambas as frações demonstrou comportamento associado aos fatores ambientais do local, como a pouca profundidade do solo, a elevada amplitude da temperatura e a deficiência hídrica e nutricional, exposição a ventos e luminosidade, dificuldade de fixação e propágulos, sementes e raízes, características desse tipo de formação (LARSON et al., 2000).

Apesar de as médias de deposição apresentarem aumento com o início do período seco, a não existência de correlações significativas pode estar demonstrando que a precipitação pouco influenciou sobre o acúmulo de biomassa, mas ressalta-se que o período de análise foi apenas de 12 meses, sendo necessário um período maior de análise.
Veneklaas (1991) afirmou que, em alguns casos, a sazonalidade da produção de serapilheira pode estar positivamente correlacionada com a precipitação, muito mais em virtude do fator mecânico - impacto da chuva, do vento, dos raios e outros - do que a periodicidade fisiológica que determina a queda sazonal das folhas, que é fração dominante da serapilheira total. Já Dias e Oliveira Filho (1997) associaram a maior queda de serapilheira durante a estação chuvosa em seu estudo em Floresta Estacional Semidecidual Montana à renovação foliar mais intensa.

\subsection{Teores dos nutrientes}

A ordem dos teores da fração "outras espécies” apresentou a mesma ordem em um estudo realizado por Vogel e Schumacher (2010), com a serapilheira acumulada em uma Floresta Estacional Semidecidual. A fração "pseudobombax" apresentou ordem semelhante à encontrada por Godinho (2011), em Floresta Estacional Semidecidual Submontana, que verificou a seguinte ordem: $\mathrm{Ca}>\mathrm{N}>\mathrm{K}>\mathrm{Mg}>\mathrm{S}>\mathrm{P}$, diferindo, em sua ordem, os elementos $\mathrm{Mg}$ e K. Como se pode verificar nesta última fração, o teor de Ca apresentou-se maior, segundo esse mesmo autor, e isso se deve ao fato de o Ca ser um componente estrutural das células do tecido vegetal, tendendo, assim, a ser um dos últimos a ser liberado para o solo via decomposição da serapilheira.

Neste estudo, os elementos de maiores teores foram o N e Ca. Segundo Vital et al. (2004), o N é o elemento que apresenta a maior transferência, seguido do Ca. Caldeira et al. (2007), avaliando a Floresta Ombrófila Mista Montana, no Estado do Paraná, evidenciou que a serapilheira acumulada é a principal via de transferência de N, K e Ca, e este último apresentou o segundo maior teor. Ao avaliar os resultados deste estudo, pôde-se verificar que a serapilheira foi a principal via de transferência de N, Ca e Mg para ambas as frações, diferindo apenas $\mathrm{K}$ dos estudos citados.

A manutenção dos teores de S na serapilheira acumulada de "pseudobombax" ao longo do ano, segundo Freney e Swaby (1975), justifica-se pelo fato de a maior parte do S no solo estar na matéria orgânica, sendo esse material o principal reservatório que, convertido por via microbiana, fica disponível para as plantas.

Os resultados da correlação deste estudo são contrários aos encontrados por Viera e Schumacher 
(2009), que, em estudo em serapilheira de Pinus taeda L., encontraram correlações positivas para os nutrientes $\mathrm{N}$ e S $(0,37$ e 0,66 , respectivamente), com a variável temperatura, e o $\mathrm{S}$ teve correlação significativa (5\% de probabilidade). Para Dias e Oliveira Filho (1997), em um estudo em Floresta Estacional Semidecidual Montana (Lavras, MG), o N e o P acompanharam a sazonalidade da queda da serapilheira, em que ocorreram os meses de maiores chuvas e, consequentemente, as maiores temperaturas.

Os resultados da Tabela 2 evidenciaram que a fração "outras espécies" é a que mais se aproximou em seus teores (para a maioria dos nutrientes), com algumas tipologias florestais, em comparação com outros estudos (GODINHO, 2013; VOGEL; SCHUMACHER, 2010).

Em relação aos teores dos micronutrientes, Caldeira et al. (2007) perceberam que seus resultados diferiram da ordem, havendo troca de $\mathrm{Zn}$, que teve maior concentração do que o B. Os elementos Fe e Mn foram os que apresentaram maiores teores na serapilheira, também observados na análise dos solos da área de estudo.

Muitos fatores afetam essas concentrações, em que a maior presença do Fe pode ser explicada pela sua baixa mobilidade. A mobilidade do Fe pode ainda ser afetada pelos aumentos nos teores de $\mathrm{P}$, deficiência de K, elevada quantidade de Mn ou por contaminação com o solo, quando é feita a coleta da serapilheira (DECHEN; NACHTIGALL, 2006; MALAVOLTA, 2006; CALDEIRA et al., 2007).

Os resultados também indicaram elevado teor do elemento Mn que, segundo Heenan e Campbel (1980), pode estar associado à contaminação do solo na amostra, assim como a capacidade das folhas em armazenar Mn caso haja bom suprimento desse no ecossistema.

A variação no acúmulo desses nutrientes dentro do período de estudo não demonstrou tendência de períodos com maior ou menor concentração. Entretanto, a correlação positiva e moderada entre o $\mathrm{Cu}$ e a precipitação também foi relatada por Viera e Schumacher (2010) em um estudo de povoamento de Pinus taeda L. Esses autores também detectaram correlação positiva, moderada $(0,67)$ e significativa $(5 \%$ de probabilidade) na variável precipitação.

\subsection{Conteúdo dos nutrientes}

Cada fração apresenta acúmulo de nutrientes diferenciado da outra, assim como ocorreu com os resultados dos teores.

Vogel e Schumacher (2010), em uma Floresta Estacional Semidecidual, obtiveram a seguinte ordem: $\mathrm{N}>\mathrm{Ca}>\mathrm{Mg}>\mathrm{K}>\mathrm{S}>\mathrm{P}$, sendo a mesma ordem para a fração "outras espécies” deste estudo.

Esses resultados corroboram o estudo de Cole e Rapp (1980), segundo os quais a serapilheira é considerada a principal via de transferência para os elementos, como o $\mathrm{N}$ e $\mathrm{Ca}$.

Haag (1985) afirmou que há variação nas espécies florestais em relação à quantidade de nutrientes retidos e devolvidos, ou seja, há espécies que retêm a maior parte dos nutrientes absorvidos, enquanto outras devolvem a grande maioria do que absorvem e há aquelas em que retenção é igual à devolução, assim como se devem considerar a idade das espécies e as condições edafoclimáticas em que elas se encontram.

Naeem et al. (1995) e Tilman et al. (1996) afirmaram que a diversidade de plantas influencia nas características do ecossistema, assim como na produção de biomassa vegetal, e as disponibilidades de nutrientes no solo estão positivamente relacionadas com a diversidade de espécies de plantas no ecossistema.

Os resultados demonstraram que os valores dos conteúdos acumulados de cada nutriente estão muito próximos a ecossistemas considerados de maior diversidade, no entanto a ordem decrescente foi diferente. Essa situação pode ser demonstrada comparada com o estudo de Godinho (2013) em Floresta Estacional Semidecidual Submontana, onde os resultados foram: 94,91 $\mathrm{kg} \mathrm{ha}^{-1}$ de $\mathrm{N} ; 4,14 \mathrm{~kg} \mathrm{ha}^{-1}$ de P; 14,03 $\mathrm{kg} \mathrm{ha}^{-1} \mathrm{de}$ $\mathrm{K} ; 161,03 \mathrm{~kg} \mathrm{ha}^{-1} \mathrm{de} \mathrm{Ca} ; 12,1 \mathrm{~kg} \mathrm{ha}^{-1} \mathrm{de} \mathrm{Mg}$; e 7,35 $\mathrm{kg} \mathrm{ha}^{-1}$ de S. Neste estudo, os valores obtidos dos nutrientes foram: $136,9 \mathrm{~kg} \mathrm{ha}^{-1}$ de $\mathrm{N} ; 6,5 \mathrm{~kg} \mathrm{ha}^{-1}$ de P; $10,6 \mathrm{~kg} \mathrm{ha}^{-1} \mathrm{de} \mathrm{K} ; 108,5 \mathrm{~kg} \mathrm{ha}^{-1}$ de Ca; 22,45 $\mathrm{kg} \mathrm{ha}^{-1}$ de $\mathrm{Mg}$; e 8,21 $\mathrm{kg} \mathrm{ha}^{-1}$ de S.

Com relação aos micronutrientes, verificou-se alto valor do $\mathrm{Fe}$ e do $\mathrm{Mn}$. Como esses valores de conteúdo têm relação direta com os teores dos nutrientes e com a biomassa das frações, os elevados valores de conteúdo desses nutrientes podem ser justificados pelo maior teor deles na serapilheira, levando-se em consideração que o valor da biomassa foi constante para todos. 
Esses resultados são semelhantes aos encontrados por Caldeira et al. (2007), que obtiveram uma ordem semelhante a deste estudo: $\mathrm{Fe}>\mathrm{Mn}>\mathrm{Zn}>\mathrm{B}>\mathrm{Cu}$, o que justifica os maiores conteúdos de Fe e Zn pela sua mobilidade e pelo fato de as folhas apresentarem maiores teores que outros tecidos da planta, além da possível contaminação por solo.

\section{CONCLUSÕES}

O acúmulo da serapilheira não se mostrou sazonal, com aporte contínuo ao longo do ano, sem grande variação entre períodos de coleta seca.

Os teores de nutrientes diferiram entre os diferentes meses do período de estudo ( $\mathrm{p}<0,05)$, com exceção do $\mathrm{S}$ da fração pseudobombax. Os elementos $\mathrm{Ne}$ e na fração, outras espécies foram influenciadas significativamente pela temperatura. Na fração pseudobombax, os elementos $\mathrm{N}$ e Fe foram influenciados pela pluviosidade e o P, pela temperatura. Nesta última fração e em ambas as variáveis, o elemento $\mathrm{Cu}$ foi influenciado.

Os nutrientes de maior disponibilidade na serapilheira foram N, Ca e Fe, em que este último pode estar indicando contaminação do material analisado pelo solo.

A vegetação local demonstrou capacidade de aporte e de manutenção da serapilheira sobre o solo, pois durante todo o ano do período de estudo ocorreu contínuo acúmulo de material.

\section{REFERÊNCIAS}

BENITES, V.M.; CAIAFA, A.N.; MENDONÇA; E.S.; SCHAEFER, C.E.Ç.; KER,J.C. Solos e vegetação nos complexos rupestres de altitude da Mantiqueira e do Espinhaço. Floresta e Ambiente, Seropédica, v. 10 , n. 1, p.76-85, 2003.

BOREM, R.A.T.; RAMOS, D.P. Variação estacional e topográfica de nutrientes na serapilheira de um fragmento de mata atlântica. Revista Cerne, Lavras, v.8, n.2, p. 42-59. 2002.

BURGHOTS, T.B.A., CAMPBELL, E.J.F., KODERMAN, P.J. Effects of tree species heteogeneity on leaf fall in primary and logged dipterocarp forest in the Ulu Segana Forest reserve, Sbah, Malasia, Journal of Tropical Ecology, Aberdeen, n 10, p. 1-26, 1994.
CALDEIRA, M.V.W.; MARQUES, R.; SOARES, R.V.; BALBINOT, R. Quantificação de serapilheira e de nutrientes - Floresta Ombrófila Mista Montana - Paraná. Revista Acadêmica, Curitiba, v.5, n.2, p. 101-116, 2007.

\section{CALDEIRA, M.V.W.; SCHUMACHER, M.V.;} VIERA, M.; GONÇALVES, E.O.; GODINHO, T.O. Ciclagem de nutrientes, via deposição e acúmulo de serapilheira, em ecossistemas florestais. In: CHICHORRO, J.F.; GARCIA, G.O.; BAUER, M.O. Tópicos em Ciências Florestais. Visconde do Rio Branco: 2010. p.57-82.

CHAMBERS, C.C.; MACMAHON, J.A. A day in the life of a seed: movement sand fates of seeds and their implications for natural and managed systems .Annual Review of Ecology and Systematics, v.25, p.263292,1994 .

\section{CARVALHO-SOBRINHO, J.G.; O gênero Pseudobombax Dugand Malvaceaes.l., Bombacoideae) no Estado da Bahia, Brasil. [Dissertação de Mestrado]. Curso de Programa de Pós-Graduação em Botânica, Universidade Estadual de Feira de Santana, Feira de Santana, BA, 2006.}

COLE, D.W.; RAPP, M. Elemental cycling in forested ecosystems. In: REICHLE, D. E. (Ed.) Dynamic properties of forest ecosystems. Cambridge: Cambridge University, 1980. p.341-409.

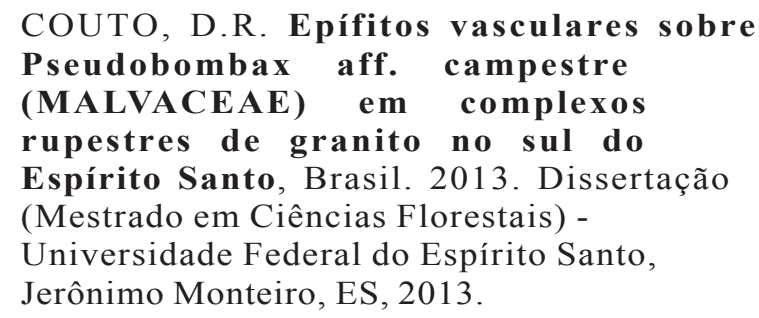

CUEVAS, E.; MEDINA, E. Nutrient dynamics within amazonian Forest ecosystems. In. Nutrient flux in the fine litterfall and efficiency of nutrient utilization. Oecologia, Rio de Janeiro, v.68, p.466-472, 1986.

DECHEN, A.R.; NACHTIGALL, G.R. Nutrição mineral de plantas. Viçosa, Sociedade Brasileira de Ciência do Solo, 2006. p.327-346. 
DIAS, H.C.T.; OLIVEIRA FILHO, A.T. Variação Temporal e espacial da produção de serapilheira em uma área de Floresta Estacional Semidecídua Montana em Lavras-MG, Revista Árvore, Viçosa-MG, v.21, n.1, p.11-26, 1997

DIAS, H.C.T.; FERNANDES FILHO,E.I.; SCHAEFER,C.E.G.R.; FONTES, L.E.F.; VENTORIM, L.B. Geoambientes do parque estadual do Ibitipoca, município de Lima Duarte-MG, Revista Árvore, Viçosa, v.26, n.6, p. 777-786, 2002.

EMBRAPA. Centro Nacional de Pesquisa de Solos. Centro Nacional de Pesquisas de Solos, Rio de Janeiro, 2009, 412p.

FACELLI, J.M.; PICKETT, S.T.A. Plant litter: its dynamics and effects on plant community structure. The Botanical Review, Lancaster, v.57, p.1-32, 1991.

FERREIRA, D.F. Manual do Sistema Sisvar para análises estatísticas. Universidade Federal de Lavras - Lavras, MG. 2000 .

FIGUEIRA, J. E. C.; VASCONCELOS NETO, J. Paepalanthus, cupins e aranhas. Ciência Hoje, v. 13, n. 75, p. 20-25, 1991.

FRENEY, J.R.; SWABY,R.J. Sulphur transformation in soils. In: McLANCHLAN,K.D. Sulphur in Australasian agriculture. Sidney, Sidney University Press, 1975.

GODINHO, T.O. CALDEIRA, M.V.W.; CALIMAN, J.P.; PREZOTTI, L.C.; WATZLAWICK, L.F.; AZEVEDO, H.C.A.; J.H.T. ROCHA. Biomassa, macronutrientes e carbono Orgânico na serapilheira depositada em trecho de floresta Estacional Semidecidual Submontana, ES.

Scientia Forrestalis, Piracicaba, v. 41, n. 97, p. 131-144, 2013

GOLLEY, F.B. Nutrient cycling and nutrient conservation. In: Tropical forest ecosystems: structure and function. Elsevier, Amsterdam, 1983. p.137-156.

HAAG, H.P. Ciclagem de nutrientes em florestas tropicais. Campinas: Fundação Cargill, 1985. 144p.
HEAL, O.W.; ANDERSON, J.M.; SWIFT, M.J. Plant litter quality and decomposition: a historical overview. In: CADISH, G.; GILLER, K.E. (Ed.). Driven by nature. Plant litter quality and decomposition. Wallingford: CAB International, 1997. p.3-30.

HEENAN, D.P.; CAMPBELL, L.C. Soybean nitrate reductase activity influenced by manganese nutrition. Plant Cell Physiology, Oxford, v. 21, n. 4, p. 731-736, 1980.

INSTITUTO BRASILEIRO DE GEOGRAFIA E ESTATÍSTICA - IBGE. 2012. Manual

Técnico da Vegetação Brasileira. 2.ed. Rio de Janeiro: 2012.

INSTITUTO NACIONAL DE METEOROLOGIA INMET -. Disponível em: http:// www.inmet.gov.br/sonabra/maps/ automaticas.php. Acesso em: Out. de 2012.

KLEINPAUL, I.S.; SCHUMACHER, M.V.; BRUN, E.J.; BRUN, F.G.K.; KLEINPAUL, J.J.

Suficiência amostral para coletas de serapilheira acumulada sobre o solo em Pinus elliottii engelm, Eucalyptus sp. e Floresta Estacional Decidual. Revista Árvore, Viçosa, v.29, n.6, p.965-972, 2005.

LARSON, D.W.;MATTHES, U.; KELLY, P.E. Cliff Ecology. Pattern and Process in Cliff Ecosystems. Cambridge: Cambridge University Press, 2000. (Cambridge Studies in Ecology).

MALAVOLTA, E. Manual de nutrição de plantas. São Paulo: Agronômica, Ceres, 2006.

MIYAZAWA, M.; PAVAN, M.A.; MURAOKA, T.; CARMO, C.A.F.S.; MELLO,W.J. Análises químicas de tecido vegetal. In: SILVA, F.C. (Ed.). Manual de análises químicas de solos, plantas e fertilizantes. Brasília: Embrapa Solos,1999. p.171-223.

NAEEM, S.; THOMPSON, L.J.; LAWLER, S.P.; LAWTON, J.H.; WOODFIN, R.M. Empirical evidence that declining species diversity may alter the performance of terrestrial ecosystems. Philosophical Transactions of the Royal Society of London, London, v. 347, p. 249-262. 1995 
ODUM, E.P. The strategy of ecosystem development. Science, Washington,v.164, p.262-270, 1969.

OLSON, J.S. Energy storage and the balance of producers and decomposers in ecological systems. Ecology, Washington, v.44, p.322-330, 1963.

RODRIGUES, A.C.G.; BARROS, N.F.; COMERFORD, N.B. Biomass and nutrient cycling in pure and mixed stands of native tree species in southeastern Bahia, Brazil. Revista Brasileira de Ciência do Solo, Viçosa, n.31, p.287-298, 2007.

PRITCHETT, W.L. Properties and management of Forest soils. New York: John Wiley, 500p. 1979.

SCHUMACHER, M. V.; BRUN, E.J.; KONIG, F.G. Análise de nutrientes para a sustentabilidade. Revista da Madeira, n. 83, agosto de 2004.

SCHUMACHER, M. V.; TRUBY, P; MARAFIGA, J.M.; VIERA, M.; SZYMCZAK, D.A. Espécies predominantes na deposição de serapilheira em fragmento de floresta estacional decidual no Rio Grande do Sul. Ciência Florestal, Santa Maria, v.21, n.3, p.479-486, jul-set.,2011.

SHIMAKURA, S.E. Correlação. In: CE003 Estatística II. Paraná: Dep. de Estatística da Universidade Federal do Paraná: Curitiba, 2006. p.71-78.

TAIZ, L.; ZEIGER, E. Plant physiology. California: Benjamin/Cummings Publishing Company, 1991. 559p.

TEDESCO, M.J.; GIANELLO, C.; BISSANI, C.A.; BOHNEN, H.; VOLKWEIS, S.J. Análise de solo, plantas e outros materiais. 2. ed. Ver. e ampl. - Porto Alegre, Universidade Federal do Rio Grande do Sul, 1995. 174p.

TILMAN, D.; WEDIN, D.; KNOPS, J. Productivity and sustainability influenced by biodiversity in grassland ecosystems. Nature, London, v 379 , p. 718-720. 1996.

VENEKLAAS, E.J. Litterfall and nutriente fluxes in two montane tropical rain forests, Colombia.

Journal of Tropical Ecology, Aberdeen, n 7, p. 319-336, 1991.

VIERA, M.; SCHUMACHER, M.V. Concentração e retranslocação de nutrientes em acículas de Pinus taeda L. Ciência Florestal, Santa Maria, v.19, n.4, p.375-382, 2009.

VIERA, M.; SCHUMACHER, M.V. Teores e aporte de nutrientes na serapilheira de Pinus taeda L., e sua relação com a temperatura do ar e pluviosidade. Revista Árvore, Viçosa, v.34, p. 85-94, 2010.

VITAL, A.R.T.; GUERRINI, I.A.; FRANKEN, W.K.; FONSECA, R.C.B. Produção de serapilheira e ciclagem de nutrientes de uma floresta estacional semidecidual em zona ripária. Revista Árvore, Viçosa, v.28, n.6, p.793-800. 2004.

VOGEL, H.L.M.; SCHUMACHER, M.V. Biomassa e Nutrientes na serapilheira em um fragmento de Floresta Estacional Semidecidual em São GabrielRS, Brasil In: FERTIBIO. Anais...Guarapari, ES, 2010.

WEDDERBURN, M.E.; CARTER, J. Litter decomposition by four functional tree types for use silvopastoral systems. Soil Biology and Biochemistry, Elmsford, v.31,n.1p.455-461,1999. 